\title{
O Ensino de Conteúdos Geográficos a partir do Hip Hop
}

\author{
The Teaching of the Geographical Contents as from the Hip Hop \\ La Enseñanza de Contenidos Geográficos a partir del Hip Hop \\ Ana Carolina dos Santos Marques ${ }^{1}$
Ricardo Lopes Fonseca
}

Recebido em 07/03/2017. Aceito em 26/04/2017

\begin{abstract}
RESUMO: O Hip Hop é um movimento cultural praticado majoritariamente pela população negra e, assim como o racismo, se manifesta no espaço geográfico e consequentemente pode ser estudado pela Geografia, possibilitando trabalhar inúmeros conteúdos. Desta forma, o presente artigo tem por objetivo investigar e compreender como o Hip Hop, por meio do pilar rap, pode ser abordado no ensino de Geografia, auxiliando na construção dos conhecimentos geográficos. O referencial teórico traz a questão racial presente no Brasil, para então conceituar o movimento Hip Hop, bem como apresentar suas características e contribuições no ensino de Geografia. Há ainda um relato acerca de uma oficina pedagógica realizada no Colégio Estadual Marcelino Champagnat em Londrina (PR) com educandos do $2^{\circ}$ ano matutino, em que foi abordado o Hip Hop e ocorreu a construção de raps por parte dos educandos. Por fim, os raps elaborados são analisados por meio da Análise de Conteúdo de Bardin (1977), buscando identificar os conteúdos da ciência geográfica presentes nestes e a importância do rap na construção e compreensão dos conteúdos no ensino de Geografia, entre eles: os problemas sociais, a economia e a luta por uma educação de qualidade.
\end{abstract}

Palavras-Chave: Hip Hop; Rap; Ensino de Geografia.

ABSTRACT: The Hip Hop is a cultural movement practiced mostly by the black population and, so as the racism, manifests in the geographic space and consequently can be studied by Geography, making it possible to study the contents of geographical science in the teaching of the discipline. Therefore, the present article has the objective to investigate and understand how Hip Hop, by means of rap branch, can be approach in the scholar Geography, helping in the construction of geographic knowledge. The theoretical reference has its the racial issue presents in Brazil, for then conceptualize the Hip Hop movement, as well as of its characteristics and contributions in scholar Geography. There is also a report about a pedagogical workshop performed at State High School Marcelino Champagnat in Londrina $(P R)$ with learners of the 2nd year of the morning period, which was approached by the Hip Hop and it occurred the construction of raps by the learners. By the end, the elaborated raps are analyzed with the content analyzes of Bardin (1977), searching to identify the contents in the geographical science presents in it and the importance of rap in the construction and understanding of contents in scholar geography, among them: the social problems, the economy and the fight for a quality education.

Key Words: Hip Hop; Rap; Scholar Geography.

RESUMEN: El Hip Hop es un movimiento cultural practicado mayoritariamente por la población negra, y así como el racismo, se manifiesta en el espacio geográfico y consecuentemente puede ser estudiado por la Geografía, posibilitando trabajar innumerables contenidos. Por lo tanto, el presente artículo tiene por objetivo investigar y comprender cómo el Hip Hop, por medio del pilar rap, puede ser abordado en la enseñanza de Geografía, auxiliando en la construcción del conocimiento geográfico. El referencial teórico trae la cuestión racial presente en Brasil, para entonces conceptualizar el movimiento Hip Hop, así como presentar sus características y contribuciones para la enseñanza de

Geografia (Londrina) v. 26. no. 2. p. 182-194, jul./dez. 2017. 
Geografía. Hay incluso un relato acerca de un taller pedagógico realizado en el Colegio Estadual Marcelino Champagnat en Londrina (Paraná) con educandos del $2^{\circ}$ año matutino, en el cual fue abordado el Hip Hop y ocurrió la construcción de raps por parte de los educandos. Por último, los raps elaborados son analizados a través del análisis de contenido de Bardin (1977), buscando identificar los contenidos de la ciencia geográfica presentes en los mismos y la importancia del rap en la construcción y comprensión de los contenidos en la enseñanza de Geografía, entre ellos: los problemas sociales, la economía y la lucha por una educación de calidad.

Palabras Clave: Hip Hop; Rap; Enseñanza de Geografía.

\section{INTRODUÇÃO}

O Hip Hop é um movimento cultural cuja origem está vinculado à população negra como forma de manifesto contra as injustiças sofrida por essa população, denunciando as situações de racismo, desigualdade racial e exclusão social pelas quais o povo negro é obrigado a conviver cotidianamente.

A escolha do Hip Hop como tema da presente pesquisa está ligada ao interesse dos autores pela questão racial. Buscou-se escolher uma linguagem que possibilitasse trabalhar este tema no ensino de Geografia e o Hip Hop caracterizava-se como um dos mais expressivos movimentos culturais praticado pela população negra, além de estar intrinsecamente ligado à Geografia por se manifestar no espaço geográfico.

Esta pesquisa objetiva investigar e compreender como o Hip Hop, por meio do pilar rap pode ser abordado no ensino de Geografia auxiliando na construção dos conhecimentos geográficos.

Uma oficina pedagógica foi organizada, planejada e aplicada no Colégio Estadual Marcelino Champagnat em Londrina (PR), a fim de comprovar se a proposta pode ser utilizada em sala de aula pelos professores de Geografia, além de que outros podem utilizála adaptando-a aos conhecimentos de suas disciplinas. Os resultados dessa metodologia são apresentados no final do artigo e interpretados à luz do método de Análise de Conteúdo de Bardin (1977).

Ao fim da pesquisa, o Hip Hop mostra-se como uma importante ferramenta para o professor de Geografia, possibilitando ao docente trabalhar inúmeros conteúdos da ciência geográfica em sala de aula, proporcionando aos educandos uma aula diferenciada e despertando o interesse destes pelo processo de aprendizagem. Desta forma, busca-se demonstrar essas significativas contribuições do Hip Hop na construção dos conhecimentos geográficos e no ensino de Geografia.

\section{QUESTÕES RACIAIS E A PRÁTICA DO HIP HOP}

O Hip Hop pode ser compreendido por meio de sua manifestação nas diversas áreas da cidade. O Grafite ${ }^{3}$ nos muros e paredes revela a subjetividade de quem o desenha, 0 break dance transmite as manifestações populares alternativas para os jovens, 
possibilitando a recreação e a competição entre os grupos. Ainda pode-se destacar a contribuição da abordagem cultural no estudo do rap, possibilitando o entendimento das vivências da população por meio das letras das músicas, carregadas de significado, Enquanto que o $D J$ fala da realidade por meio da música, elaborando colagens rítmicas que dão base aos outros pilares, como o break dance e o rap (MACHADO, 2012).

Considerando que o Hip Hop é praticado em sua maioria pela população negra e por meio do emissor da mensagem denuncia o racismo, portanto, torna-se fundamental dialogar acerca da questão racial quando se discute essa manifestação cultural na educação.

Neste sentido, o racismo não é uma prática recente no Brasil. De acordo com Sant' Ana (2005), as maiores vítimas do racismo na sociedade são a população negra. O autor ressalta que o ponto de partida da discriminação racial foi o século $\mathrm{XV}$, em que os não brancos (negros e indígenas) eram alvo dos colonizadores europeus, que se julgavam superiores, dominavam os povos, destruindo sua cultura e impondo sua superioridade, deste modo, o racismo foi uma ideologia criada a serviço da dominação e da justificativa do processo de colonização, em que os negros e indígenas foram considerados "selvagens", sendo necessário impor a estes povos à civilização.

Sant' Ana (2005) aponta que o racismo fortaleceu-se no século XIX, por meio da produção de justificativas que adquiriram forma de tratados e teses cientificas, procurando explicar a superioridade da raça branca sobre as raças não brancas. O século XIX foi o da consolidação das doutrinas racistas e esses ideais permanecem até os dias atuais:

Tem-se a impressão de que o negro e o índio foram vítimas de uma conspiração bem planejada durante todos esses séculos, onde foram elaboradas doutrinas com falsa base bíblica e filosófica, bem como tentativas de comprovação de teorias com uma falsa base científica, que não resistiram ao tempo. Mas as marcas do racismo e suas maléficas conseqüências permaneceram, já que estes preconceitos sobrevivem às gerações. A discriminação e o preconceito foram se fortalecendo no dia-adia, criando fortíssimas raízes no imaginário popular, chegando ao ponto no qual nos encontramos hoje. O racismo tomou-se uma ideologia bem elaborada, sendo fruto' da ciência européia a serviço da dominação sobre a América, Ásia e África. E esta ideologia racista ganha força a partir da escravidão negra, adquirindo estatuto de teoria após a revolução industrial europeia (SANT' ANA, 2005, p. 49).

Segundo Santa' Ana (2005), o racismo é a pior forma de discriminação porque o sujeito não pode mudar as características raciais que a natureza lhe deu. O autor aponta que no Brasil o racismo "antinegro" está intimamente ligado à cor da pele, possuindo um conteúdo cultural muito forte. Há um domínio cultural, estético e econômico da população de cor de pele branca, o que possibilita entender o forte mito em torno da cor do negro: "Há uma violenta carga emocional em torno de sua cor. O negro vive em um mundo branco, 
criado à imagem do branco e basicamente dominado pelo branco" (SANT' ANA, 2005, p. $59)$.

O racismo nasce no Brasil associado à escravidão e se consolida após a abolição desta em 1888, com base em teses de inferioridade biológica dos negros e difunde-se pelo país como matriz para a interpretação do desenvolvimento nacional. A abolição da escravidão colocou a população negra em uma situação de igualdade política e civil em relação aos demais cidadãos, porém as possibilidades de inclusão socioeconômica dessa população eram extremamente limitadas. A Lei de Terras de 1850, a abolição sem qualquer mecanismo de proteção ao negro recém-liberto e a política de migração baseada na ideologia de branqueamento da população perpetuaram o quadro social de pobreza e miséria do negro que vai buscar espaço nos interstícios possíveis, como os pequenos serviços, o trabalho precário e as periferias como local de moradia (THEODORO, 2008).

Desta forma, perpetuou por décadas existência da precariedade, informalidade, desigualdades e da marginalização do trabalho realizado pelo negro no Brasil. Silva (2006) destaca que a população negra vive um cotidiano de discriminações raciais que interferem fundamentalmente em sua trajetória e seu destino, marcados pela resistência:

A resistência do negro ao longo da história sempre foi vista como uma ameaça contra a sociedade dominante. A luta do negro para não ser totalmente destruído, cultural, social e biologicamente, foi uma constante. A história do negro no Brasil é uma história de resistências (SILVA, 2006, p. 39).

Considerando a trajetória do povo negro desde a abolição, e o atual cenário em que vive, marcado pelo racismo e pela desigualdade social, o Hip Hop expressa por meio do rap, grafite, break dance e $D J$, a resistência negra, possibilitando sua utilização para a denúncia da discriminação racial sofrida, divulgação das vivências e cultura da população negra. Além disso, o movimento apresenta inúmeras possibilidades de utilização para o ensino de Geografia, caracterizando-se como uma importante ferramenta que pode ser usada pelo professor em sala de aula, proporcionando aos educandos uma aula diferenciada e um aprendizado efetivo.

\section{O HIP HOP NO ENSINO DE GEOGRAFIA}

A escolha do Hip Hop como tema da presente pesquisa está ligada ao interesse dos autores pela questão racial. Buscou-se escolher uma linguagem que possibilitasse trabalhar este tema no ensino de Geografia. É importante destacar que o Hip Hop caracteriza-se como um dos mais expressivos movimentos culturais, principalmente, pela população negra, além de estar intrinsecamente ligado à Geografia por se manifestar no espaço geográfico. 
De acordo com Oliveira (2012), o Hip Hop é um movimento cultural que surgiu nos guetos de Nova lorque entre os anos de 1960 e 1970, porém, o movimento não é uma invenção propriamente estadunidense, ele foi criado por Kool Herc, um D.J. (disc jockey) jamaicano que, em suas viagens entre o Caribe e a África do Sul, conheceu os cantos falados de grupos que se assemelhavam ao reggae e levou essa tradição aos guetos nova iorquinos.

Segundo Machado (2012), os guetos enfrentavam diversos problemas sociais como pobreza, racismo, violência, tráfico de drogas e ausência de infraestrutura e educação. Deste modo, o movimento surgiu como forma de reação a esses problemas e aos conflitos sociais sofridos pelas classes populares:

É o que seus praticantes denominam de cultura das ruas, um movimento de reivindicações de espaço e voz das periferias, traduzido nas letras questionadoras e por vezes agressivas que buscavam, quem sabe, ferir os ouvidos das classes dominantes. Possuíam um ritmo forte e intenso e eram traduzidas nas imagens grafitadas pelos muros das cidades (MACHADO, 2012, p. 69).

No Brasil, o Hip Hop surgiu nos anos 1970 e 1980 com maior expressividade em São Paulo. Turra Neto (2013) ressalta que os Bailes Black nos anos de 1970 possibilitaram uma sintonia entre jovens negros e negras dos grandes centros urbanos, com as modas e debates que aconteciam nos Estados Unidos. Nesse contexto, o movimento encontrou um ambiente propício para sua manifestação, desenvolvendo-se numa conjuntura de afirmação da população negra no espaço urbano.

Santos (2013) afirma que o movimento Hip Hop possui quatro elementos: o DJ, o Break Dance, o Grafite e o MC+Rap. O DJ é o operador do toca discos que faz as bases e colagens rítmicas, sobre as quais se articulam os outros elementos, atualmente ele é considerado um músico (MACHADO, 2012).

O Break Dance representa a dança do movimento. Há uma ocupação simbólica realizada pelos dançarinos que se deslocam muitas vezes da periferia para ocupar as áreas centrais da cidade. O Grafite é uma forma de apropriação da cidade representada por desenhos e mensagens feitos em paredes ou muros, sendo comumente confundido com pichações e considerado vandalismo (SANTOS, 2013).

O MC é o personagem que faz o rap. A palavra rap significa "ritmo e poesia" (do inglês, rhythm and poetry), o ritmo é dado pela base musical e a melodia por meio do rap (SANTOS, 2013). Esse elemento manifesta-se por meio da música e relata os problemas, as injustiças, as carências e as vivências das classes populares:

A manifestação musical no movimento hip-hop é o RAP (rhythm and poetry). É por meio dela que o movimento pôde ser inserido na trajetória 
histórica de resistência dos negros, desde a diáspora africana, até as lutas contra a discriminação racial, na qual a afirmação cultural através da música sempre foi um elemento importante. O Rap é o elemento que alinhava os demais na cultura e num movimento social (TURRA NETO, 2013, p. 4).

De acordo com Guimarães (2007), o rap procura fazer da música um instrumento de divulgação e denúncia da violência, da discriminação e das desigualdades sofridas por jovens negros e mestiços. O autor salienta que o rap age como um canal de comunicação, mostrando como as identidades se reencontram no tempo e no espaço e relacionam-se com o global e o local, disseminando a narrativa da violência e das desigualdades para a cena musical, criando, desta forma, novas referências para a cultura.

Por meio do rap é possível trabalhar diversos conceitos geográficos:

\begin{abstract}
Muitos educandos se identificam com o rap, e essas letras trazem uma reflexão sobre a situação da sociedade e do meio em que esses sujeitos se encontram, sendo possível desenvolver e aprofundar os conteúdos da disciplina de Geografia, estimulando-os a refletir e a debater a sua própria realidade (SILVA; PIRES, 2014, p. 2).
\end{abstract}

Desta forma, o rap possibilita trabalhar com os educandos conteúdos relacionados ao espaço urbano e às desigualdades presentes neste, considerando que as letras apresentam as injustiças presentes na realidade, ressalta a exclusão social e os problemas vivenciados pelas classes populares.

Há a possibilidade de abordar as categorias da Geografia, como a afetividade que os moradores da periferia têm com seu Lugar por meio das vivências e da relação com vizinhos. Os conflitos existentes nas comunidades ressaltam as relações de poder, sendo possível trabalhar as categorias Território e de Região com os educandos. A descrição dos lugares presentes nas letras das músicas proporciona a abordagem da categoria de Paisagem e a Socioambiental pode ser trabalhada exaltando-se as dinâmicas existentes entre o homem e a natureza.

Ao solicitar a construção de letras de rap a respeito de algum conteúdo geográfico, o professor possibilita aos educandos expressarem sua criatividade e aplicarem seus conhecimentos em uma linguagem de fácil entendimento, aprofundando os conteúdos trabalhados, além de proporcionar uma interação entre os próprios educandos e o professor. Deste modo, o rap evidencia-se como uma importante ferramenta que pode ser utilizada nas aulas de Geografia, fato evidenciado pela oficina aplicada e discutida a seguir.

\title{
O PAPEL DO RAP NA COMPREENSÃO DOS CONTEÚDOS GEOGRÁFICOS
}

A fim de compreender como o Hip Hop, por meio do pilar rap, poderia auxiliar na compreensão dos conteúdos de Geografia, foi organizada e planejada uma oficina 
abordando o tema para ser aplicada no Colégio Estadual Marcelino Champagnat, Londrina (PR).

\section{Procedimentos metodológicos}

A oficina foi realizada com uma turma de $2^{\circ}$ ano matutino, constituída por 26 educandos. Inicialmente, a proposta foi explicada para os educandos e em seguida foi discutido questões referentes ao Hip Hop, tais como: sua origem, características e pilares. Posteriormente, ocorreu a interpretação de letras de rap ${ }^{1}$ que possuíam conteúdos de Geografia em suas rimas, como por exemplo, desigualdade social, processo migratório e globalização. Os educandos foram incitados a contribuir a todo o momento para as interpretações, sendo que estes leram e falaram o que entendiam das letras, sempre procurando enfatizar conteúdos de Geografia. Em seguida, os educandos foram divididos em trios e orientados a construir letras de rap, abordando conteúdos de Geografia de sua preferência.

Para interpretação e análise das músicas, utilizou-se como metodologia a Análise de Conteúdo, que segundo Bardin (1977):

[...] pode, teoricamente, apoiar-se ou reportar-se aos elementos básicos do mecanismo clássico da comunicação: a mensagem (significação e código) e seu suporte ou canal, de uma parte; o emissor e receptor, de outra parte, como polos de inferência (comuns) propriamente ditos. (Tradução nossa BARDIN, 1977, p. 169).

Deste modo, a Análise de Conteúdo evidencia-se como ferramenta que pode ser utilizada na compreensão de significado que os atores sociais expõem em seus pronunciamentos, possibilitando, ao pesquisar, realizar interpretações do material coletado por meio de categorização.

O modelo de categorização elaborado por Fonseca (2015, p. 96) e baseado na Análise de Conteúdo de Bardin (1977) foi utilizado para analisar os resultados desta pesquisa. Os quadros de análise possuem uma descrição da categoria identificada, unidades de registro (UR), exemplos de verbalizações utilizados pelos educandos, frequência relativa com que aparecem as verbalizações e um metatexto em que são discutidos os resultados obtidos por meio do quadro.

\section{Resultados obtidos}

Durante a construção dos raps, os educandos optaram por abordar os temas: problemas sociais, aspectos da economia e assuntos relacionados ao currículo. A seguir

\footnotetext{
${ }^{1}$ As letras de rap utilizadas nesta oficina foram: Racismo é Burrice - Gabriel O Pensador; Homem na estrada - Racionais Mc's; Negro Drama - Racionais Mc's; Contraste Social - MV Bill; Rap da Poluição Ambiental - Área Restrita; Globalização (Rap Geográfico) - Bran Kobran.
} 
são apresentados e discutidos nos quadros 01, 02 e 03, os resultados obtidos por meio da categorização com base na Análise de Conteúdo.

O Quadro 01 evidencia como os educandos estão atentos para os problemas sociais presentes no espaço geográfico, eles demonstram interesse pelas questões sociais e conhecimento acerca destas, sendo que muitos dos problemas citados podem fazer parte de seu cotidiano. A Geografia mostra-se como importante disciplina na criação da consciência crítica desses educandos, possibilitando a estes por meio da abordagem de diversos conteúdos como os problemas sociais, a expansão dessa ação, tornando-os seres reflexivos e incentivando-os a se reconhecer enquanto sujeito social atuante no espaço geográfico.

Quadro 01: Músicas que abordaram problemas sociais

\begin{tabular}{|c|c|c|}
\hline \multicolumn{3}{|l|}{ CATEGORIA: Problemas soci } \\
\hline \multicolumn{3}{|c|}{$\begin{array}{l}\text { De acordo com Francisco (2016), os problemas sociais tiveram origem durante o processo de } \\
\text { urbanização no Brasil que se intensificou a partir da década de } 1950 \text {. Neste período as atividades } \\
\text { industriais se expandiram, atraindo milhares de pessoas para as cidades. Porém, as cidades não } \\
\text { estavam preparadas para receber tal contingente populacional. Consequentemente, com a falta de } \\
\text { um planejamento urbano adequado surgiram vários problemas de ordem social, tais como: falta de } \\
\text { moradias adequadas, o desemprego, falta de saúde, educação e segurança, a violência e a } \\
\text { desigualdade social, por exemplo. }\end{array}$} \\
\hline UNIDADES DE REGISTRO & $\begin{array}{l}\text { EXEMPLOS DE } \\
\text { VERBALIZAÇÕES }\end{array}$ & FREQUÊNCIA RELATIVA \\
\hline UR1 - Racismo & $\begin{array}{l}\text { Racismo; negro; preconceito; } \\
\text { desvalorização; bullying; } \\
\text { cultural; desprezo; escravo; } \\
\text { cadeia. }\end{array}$ & $41 \%$ \\
\hline UR2 - Desigualdade social & $\begin{array}{l}\text { Pobreza; pobre; fome; } \\
\text { desigualdade; desnutrição; } \\
\text { periferias; miséria; crime; } \\
\text { capitalismo; descaso; falta de } \\
\text { infraestrutura; }\end{array}$ & $59 \%$ \\
\hline \multicolumn{3}{|c|}{ METATEXTO } \\
\hline \multicolumn{3}{|c|}{$\begin{array}{l}\text { Os educandos, em sua maioria, abordaram o racismo e as desigualdades sociais em suas } \\
\text { músicas, classificados aqui na categoria de problemas sociais. Os educandos expuseram a } \\
\text { desigualdade presente no espaço geográfico, explicitando a relação do rico x pobre, do descaso do } \\
\text { governo com a população pobre, da falta de educação, saúde e infraestrutura para essas } \\
\text { populações, além da caracterização das periferias. Quanto ao racismo, os educandos destacaram } \\
\text { o negro como excluído na sociedade, condenando a discriminação que a população negra sofre, } \\
\text { criticando estereótipos de bandido e burro que são atribuídos a essa população e onde geralmente } \\
\text { vivem, ou seja, nas periferias da cidade, revelando as desigualdades no espaço geográfico. Desta } \\
\text { forma, o professor de Geografia pode trabalhar diversos conteúdos com os educandos como: as } \\
\text { desigualdades raciais e sociais que marcam o espaço geográfico, as intencionalidades dos atores } \\
\text { hegemônicos que modificam este espaço em seu favor, destinando a maioria da população à } \\
\text { exclusão social, a espacialização da população negra nas cidades do Brasil, as condições de vida } \\
\text { nas periferias e as relações sociais, que são estruturadas com base no racismo, sendo que a } \\
\text { população negra recebe tratamento desigual em diversas situações como, por exemplo, no acesso } \\
\text { dos empregos com maior salário e prestigio social. }\end{array}$} \\
\hline
\end{tabular}

Fonte: os próprios autores.

Com base no Quadro 02, nota-se o interesse dos educandos por assuntos ligados à economia, ao capitalismo e à ação do Estado, demonstrando a importância da Geografia na 
construção desses conhecimentos e na criação da percepção da espacialidade dos fenômenos e ações advindas do sistema capitalista e materializados no espaço geográfico.

O Quadro 03 aponta que muitos educandos percebem a importância da educação, considerando-a um meio de ultrapassar sua condição social e melhorar de vida. Eles evidenciam a preocupação com o atual cenário do ensino brasileiro e ressaltam a importância da construção conjunta de melhorias na sociedade como um todo, sendo que um dos caminhos dessa mudança é a educação.

Quadro 02: Músicas que abordaram aspectos da economia

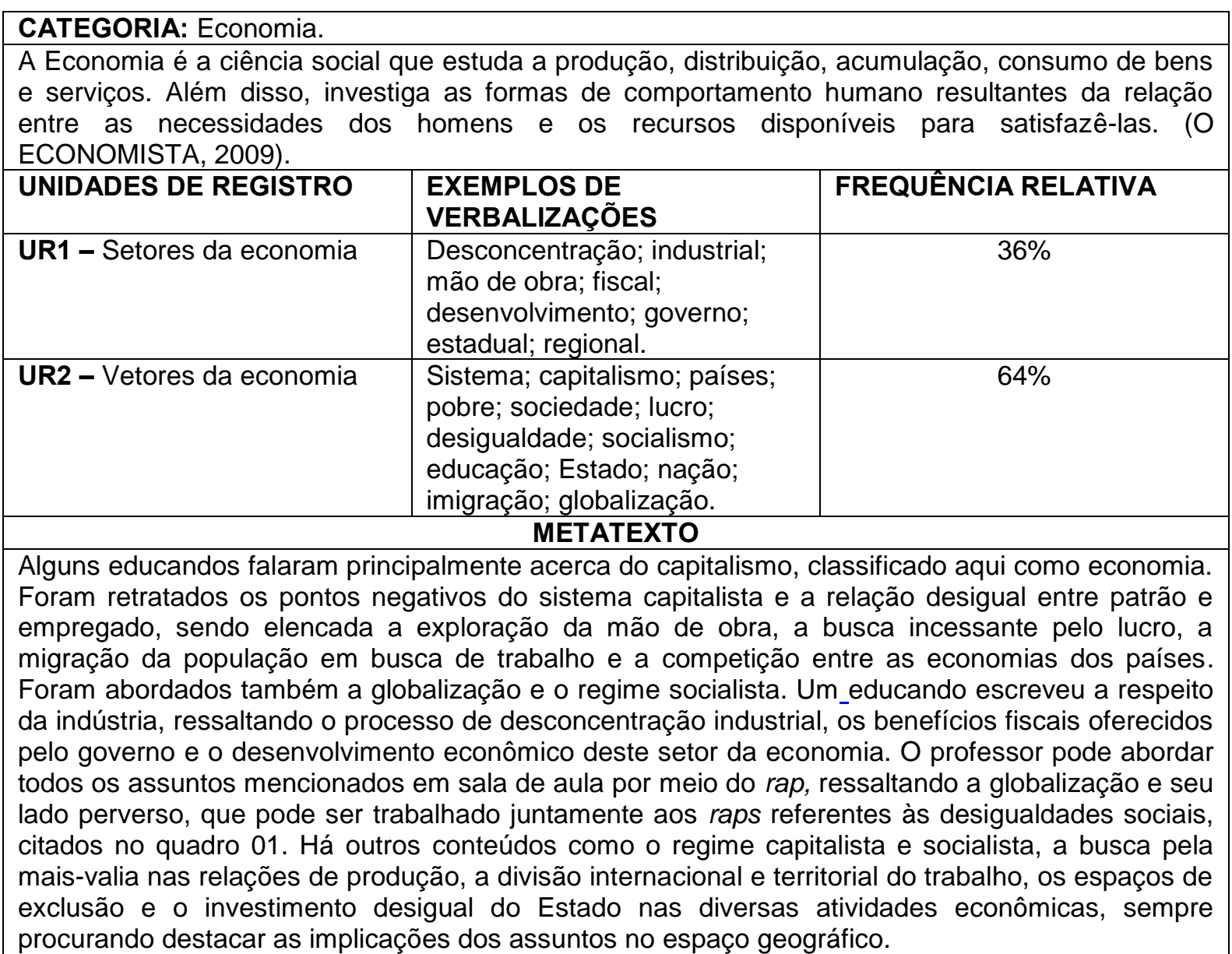

Fonte: os próprios autores.

Ao fim da oficina, os educandos responderam à questão: "Você considera que o rap auxilia a compreender os conteúdos da disciplina de Geografia?". Todos responderam que sim, ressaltando que gostam de música e que esta pode facilitar o aprendizado dos conteúdos, como evidenciado nas seguintes falas: "Sim, pois a música fica na cabeça", "Porque a letra de música é mais direta, é mais fácil decorar uma letra de música do que um texto", "Porque fica mais fácil a compreensão e ativa a vontade de aprender mais", "Pois eu presto mais atenção" e "Porque somos jovens e precisamos de algo que nos faz abrir mais a mente". Desta forma, verifica-se o interesse dos educandos por música e como esta pode 
ser um recurso pedagógico importante para os debates dos conteúdos geográficos, possibilitando ao educando realizar uma reflexão crítica e reconhecer os fenômenos sociais, políticos, econômicos e culturais, despertando sua criatividade, imaginação, sensibilidade e capacidade de interpretação.

Por meio da análise realizada comprovam-se as grandes contribuições do rap para o ensino de Geografia, proporcionando ao professor a organização de uma aula diferenciada que desperte o interesse dos educandos. O rap possibilita a abordagem de inúmeros conteúdos da ciência geográfica, como os já citados ao longo desta pesquisa, além de evidenciar a história da população negra ao longo do tempo que utiliza essa ferramenta como meio de denúncia das injustiças e desigualdades presentes no espaço geográfico.

Quadro 03: Músicas que abordaram assuntos relacionados ao currículo

CATEGORIA: Luta por uma Educação de Qualidade.

As políticas públicas nacionais voltadas para uma educação de qualidade têm falhado frente às necessidades que são almejadas por uma população histórica e socialmente segregada. O Estado oferece uma escola pública de ensino básico que privilegia um processo de aprendizagem mecânico, técnico, com inúmeras falhas, tanto na formação de professores quanto nos processos de ensino. De acordo com Dourado e Oliveira (2009, p. 203), faz-se necessária a compreensão de que "qualidade é um conceito histórico, que se altera no tempo e no espaço, ou seja, o alcance do referido conceito vincula-se às demandas e exigências sociais de um dado processo histórico".

\begin{tabular}{|l|l|c|}
\hline UNIDADES DE REGISTRO & $\begin{array}{l}\text { EXEMPLOS DE } \\
\text { VERBALIZAÇÕES }\end{array}$ & FREQUÊNCIA RELATIVA \\
\hline UR1 - Escola & $\begin{array}{l}\text { Educação; governo; corrupção; } \\
\text { alunos; povo; escola; evolução; } \\
\text { valorização; revolução; pobre. }\end{array}$ & $55 \%$ \\
\hline UR2 - Reforma do ensino & $\begin{array}{l}\text { Mobilizção; direito; } \\
\text { manifestação; cartazes; faixas; } \\
\text { indignação; rua; revolta; } \\
\text { ensino. }\end{array}$ & $45 \%$ \\
\hline \multicolumn{2}{|c|}{ METATEXTO } \\
\hline
\end{tabular}

Alguns educandos abordaram a educação, a escola e a reforma do ensino brasileiro, assuntos categorizados como luta por uma educação de qualidade. $O$ interesse dos educandos pelo tema em questão está relacionado a indignação destes quanto a reforma educacional que vinha sendo debatida na esfera federal. Este cenário influenciou os educandos na composição das letras de rap, evidenciando a importância da participação destes jovens na luta por um sistema educacional de qualidade. Acerca da escola, ressaltaram a importância da educação, a falta de investimentos do governo, a importância da escola para o povo, a importância do conhecimento para a revolução da sociedade e a importância da educação na superação das condições de pobreza. Quanto à reforma do ensino, os educandos destacaram a importância das mobilizações e manifestações da população nas ruas, destacando sua revolta e indignação com a atual situação do ensino brasileiro, além de afirmar que a educação é um direito de todos e precisa ser construída com a colaboração de toda a população. Esta categoria expressa a relevância da Geografia na construção da cidadania, desta forma, o educador pode trabalhar a importância do reconhecimento dos educandos enquanto cidadãos e sujeitos sociais que fazem parte do espaço geográfico e que podem atuar efetivamente em sua realidade, além de possibilitar a abordagem das intencionalidades que marcam o espaço geográfico, modificando suas dinâmicas e formas.

Fonte: os próprios autores. 


\section{CONSIDERAÇÕES FINAIS}

Ao fim desta pesquisa, conclui-se que o Hip Hop oferece ao ensino de Geografia inúmeras possibilidades de aplicação em sala de aula, principalmente por meio do rap (pilar do movimento e um dos focos desta pesquisa), proporcionando aos educandos um aprendizado efetivo por intermédio de uma ferramenta que os agrada, sendo esta, a música.

O negro até os dias atuais sofre com o racismo e a discriminação racial, assim como as classes populares vivem em desigualdade perante a uma parte população que possui uma maior poder aquisitivo, essas injustiças que marcam a sociedade brasileira são geralmente expressas no rap.

Faz-se importante que, ao trabalhar o Hip Hop em sala de aula, o professor ressalte a importância deste movimento para a população negra. O movimento simboliza a resistência do negro no espaço geográfico e todas as desigualdades presentes neste, divulgando o preconceito, as vivências e cultura do negro para que toda a história dessa população não seja esquecida e ignorada como foi durante longo tempo.

Por fim, é importante salientar as possibilidades de utilização dos outros pilares do Hip Hop, Break Dance, D.J e Grafite no ensino de Geografia. É possível abordar conteúdos relacionados às dinâmicas espaciais utilizando o Break Dance, visto que os dançarinos não se restringem a seus locais de origem, mas sim permeiam por todos os cantos da cidade levando sua arte. O pilar D.J, por estar relacionado com a questão da musicalidade, dos ritmos e dos instrumentos, pode contribuir com os demais pilares oferecendo mixagens para as músicas, além de um ambiente descontraído para a realização de aulas. E o graffite permite ao professor abordar os conteúdos geográficos interpretando os desenhos pintados nos muros da cidade. Essas são só algumas contribuições do Hip Hop, movimento que como mostrado nesta pesquisa, possui grande valor para o ensino de Geografia.

\section{REFERÊNCIAS}

BARDIN, L. L'analyse de contenu. 8ª édition corrigée. Paris: Presses Universitaires de France, 1977. 291 p.

CLAVAL, Paul. "A volta do cultural” na geografia. Mercator, Fortaleza, v. 1, n. 1, p. 19-28, 2002.

CLAVAL, Paul. Geografia Cultural: um balanço. Revista de Geografia, Londrina, v. 20, n.3, p. 5-24, set./dez. 2011.

CORRÊA, Roberto Lobato; ROSENDAHL, Zeny. A Geografia Cultural no Brasil. Anpege, Rio de Janeiro, n. 2, p. 97-102, 2005.

DOURADO, Luiz Fernandes; OLIVEIRA, João Ferreira de. A qualidade da educação:

perspectivas e desafios. Cad. CEDES [online]. 2009, vol.29, n.78, pp. 201-215. 
FONSECA, Ricardo Lopes. Avaliação da preparação de graduandos de Geografia para a inclusão de alunos com necessidades educacionais especiais. 2015. 183 fls. Tese (Doutorado em Geografia) - Universidade Estadual de Londrina, Londrina, 2015.

FRANCISCO, Wagner de Cerqueira e. Problemas sociais nas cidades do Brasil. 2016. Disponível em: <http://mundoeducacao.bol.uol.com.br/geografia/problemas-sociais-nascidades-brasil.htm>. Acesso em: 12 out. 2016.

GUIMARÃES, Maria Eduarda Araujo. A globalização e as novas identidades: o exemplo do rap. Perpectivas, São Paulo, v. 31, p. 169-186, jan./jun., 2007.

MACHADO, Carlos Geovani Ramos. O ensino de Geografia e o hip hop. 2012. 176 fls. Dissertação (Mestrado em Geografia) - Universidade Federal do Rio Grande do Sul, Porto Alegre, 2012.

O ECONOMISTA. Conceito de economia. 2009. Disponível em: <http://www.oeconomista.com.br/conceito-de-economia/>. Acesso em: 12 out. 2016.

OLIVEIRA, Denílson Araújo de. Juventude e territorialidades urbanas: uma análise do hip hop no Rio de Janeiro. Revista de Geografia, Juiz de Fora, v. 2, n. 1, p. 1-8, 2012.

SANT' ANA, Antonio Olimpio. História e Conceitos Básicos sobre o Racismo e seus Derivados. In: MUNANGA, Kabengele (Org.). Superando o Racismo na escola. 2. ed. Brasília: Ministério da Educação, Secretária de Educação Continuada, Alfabetização e Diversidade, 2005, p. 39-67.

SANTOS, Luiz Henrique dos. As letras de rap do movimento hip-hop como desdobramento do processo de segregação sócioespacial: antigamente quilombos, hoje periferia. 2013. 103 fls. Dissertação (Mestrado em Geografia) - Universidade Estadual Paulista, Rio Claro, 2013.

SCHMIDT, Elizabeth Silveira. Currículo: uma abordagem conceitual e histórica. Publicatio UEPG, Ponta Grossa, v. 11, n.1, p. 59-69, jun. 20003.

SILVA, Ademir José da. PIRES, Mateus Marchesan. As letras de rap como recurso metodológico no ensino de Geografia e na percepção do espaço vivido. Cadernos PDE, Paraná. v. 1, p. 1-15, 2014.

SILVA, Maria Nilza da. Nem para todos é a cidade: segregação urbana e racial em São Paulo. 1 ed. Brasília, DF: Fundação Cultural Palmares, 2006. 232 p.

THEODORO, Mário. A formação do mercado de trabalho e a questão racial no Brasil. In:

(Org.). As políticas públicas e a desigualdade racial no Brasil: 120 anos após a abolição. Brasil: Ipea, 2008, p. 15-43.

TURRA NETO, Nécio. Movimento hip-hop do mundo ao lugar: difusão e territorialização. Revista de Geografia, Juiz de Fora, v.1, p. 1-11, 2013.

\footnotetext{
${ }^{1}$ Graduanda em Geografia pela Universidade Estadual de Londrina, Campus Universitário. CEP: 86.051-990, Londrina - Paraná. Caixa Postal: 6001, Londrina - Paraná, anaaa0@hotmail.com

2 Licenciado em Geografia pela Universidade Estadual de Maringá. Doutor em Geografia pelo Programa de Pós Graduação em Geografia da Universidade Estadual de Londrina. Docente do Departamento de Geociências da Universidade Estadual de Londrina. Campus Universitário. CEP: 86.051-990, Londrina - Paraná. Caixa Postal: 6001, ricardolopesfonseca@hotmail.com
} 
${ }^{3}$ Segundo Machado (2012, p. 74): "Grafite ou Graffiti (do italiano graffiti, plural de graffito) significa "marca ou inscrição feita em um muro", era o nome dado às inscrições feitas em paredes desde o Império Romano". Portanto, neste artigo, será utilizada a grafia 'Grafite'. 